\title{
INVESTIGATION OF THE CAUSES WHICH LED TO THE OCCURRENCE OF A FIRE IN A GAS DESULPHURISATION INSTALLATION \\ - CASE STUDY -
}

\author{
Tomescu Cristian, \\ National Institute for Research and Development in Mine Safety and Protection to Explosion - INSEMEX \\ Petroşani, City Petroşani, Country Romania, e-mail cristian.tomescu@insemex.ro
}

Lupu Constantin,

National Institute for Research and Development in Mine Safety and Protection to Explosion - INSEMEX Petroşani, City Petroşani, Country Romania, e-mail constantin.lupu@insemex.ro

Cioclea Doru,

National Institute for Research and Development in Mine Safety and Protection to Explosion - INSEMEX Petroşani, City Petroşani, Country Romania, e-mail doru.cioclea@insemex.ro

\author{
Păsculescu Vlad-Mihai \\ National Institute for Research and Development in Mine Safety and Protection to Explosion - INSEMEX \\ Petroşani, City Petroşani, Country Romania, e-mail vlad.pasculescu@insemex.rot
}

\begin{abstract}
T A hazardous incident occurred in the summer of 2011 within an industrial platform belonging to a thermal-power plant located in the south-western part of Romania. The event which affected the wet chimney of the gas desulphurisation installation was a fire, triggered at a height of $54 \mathrm{~m}$. It was liquidated by the team for emergency situations, but there occurred important material losses. There weren't any human losses. In order to elucidate the objective and subjective causes which led to the occurrence of this event, there were carried out researches, there were made assumptions, there were studied the ignition sources, there were carried out tests on work materials, whose modelling provided the mechanism of the fire, and their analyses provided the result of the investigations.
\end{abstract}

Key words: absorber, fire, flammable materials, gas desulphurisation, worker

\section{Introduction}

The desulphurisation installation was under construction, within a project for reducing the pollution with gases emitted by the coal driven thermal-power plant, project in which participated several multi-national companies specialized in civil engineering, metal engineering, electrical engineering and automation, insulation constructions and industrial rubberizing. The final product of the gas desulphurisation installation is the calcium sulphide $\left(\mathrm{CaSO}_{4}\right)$, which is used after that for manufacturing gypsum boards.

The event occurred in the evening at 09:30 pm and had as starting point the mobile scaffold located on the platform at elevation +54.500 of the absorber, which is a component of the above mentioned installation, at the junction of shell ring no.9 with shell ring no. 10.

The event generated a series of thermal and chemical effects: burnings over the outside surface of the chimney (approx.542 $\mathrm{m}^{2}$ ), burning of elements which compose the mobile scaffold, the electrical installation and work equipment, and of solid particles of ash deposited inside and outside the chimney.

\section{Smoke Chimney Achievement Technology and the Fire}

\subsection{Chimney achievement}

In order to have a detailed image of the circumstances which led to the occurrence of the event, there are taken into account the technology and materials used for achieving the chimney.

The chimney is formed by the joint of 15 pre-fabricated shell rings made of polyester reinforced with glass fibre in combination with binding elements and which have an internal diameter of $7.5 \mathrm{~m}$ and heights of $4.3-4.6 \mathrm{~m}$. 
The weights of the shell rings range between 7 and 12 tons according to their thickness (calculated in accordance with the role of each shell ring in the structure of the chimney) and according to their attached auxiliary elements. The rising of the chimney is carried out in two stages:

- lifting/positioning shell ring;

- achieving the junction between two shell rings.

\subsubsection{Shell ring lifting/positioning}

The phases for lifting/positioning a shell ring are the following:

- The lifting of the achieved chimney up to a point with the help of hydraulic jacks installed at elevation +112 ;

- Once the mobile trolley has been released (the chimney has been lifted enough) this one moves from point A (chimney assembly) to point A' (placing the shell ring on the mobile trolley);

- The shell ring is lifted from 0 elevation to +54.500 elevation with the help of the high tonnage crane

- The shell ring is introduced into the mobile scaffold from the trolley;

- It is positioned so that axis 0 of the shell ring shall be collinear with axis 0 of the chimney, which is marked on the mobile trolley;

- The mobile trolley is moved from point A' to point A (extremes of the pathway which are equipped with stopper);

- The chimney is dropped down to a distance of approximately $1 \mathrm{~m}$ from the shell ring placed on the mobile trolley;

- The 8 guiding/reinforcing elements are mounted on the superior edge of the new introduced shell ring, in equidistant positions. One fastening element is composed of two flat bar cover plates jointed with screw and nut and which have flared shape at the joint area in order to ensure guidance, the operation involving a drilling of the shell ring, which is carried out on-site using a drill.

- The chimney is dropped down to a minim distance, of $1 \mathrm{~cm}$ from the shell ring to be attached (the cut ends present unevenness);

- The two shell rings are mechanically hardened by tightening the nuts of the guidance/stiffening elements.

\subsubsection{Achieving the junction between two shell rings}

The phases for achieving the junction between two shell rings:

- Preparing the surfaces by polishing: the ends of the shell rings are polished over the entire circumference, inside and outside, over a width of $25-30 \mathrm{~cm}$ for each shell ring. The operation is carried out using the angle grinder, with the work element being a sandpaper disc on paper support. The resulted dust is removed with a cloth from the polished surface;

- The interstice between the shell rings is covered with paste. The paste is a mixture of resins, NL accelerator, glass and aerosol microspheres, in defined proportions. This is prepared in the main area for material storage in quantities of 20-25 kg finite product, quantity that covers the necessary for a junction, the paste having no workability limit. The container with prepared paste is lifted and transported in the work area. In usage, there are used small amounts (hundreds grams) to which there is added ANDRONOX hardener. The homogenisation is done over a support surface from plywood using a metallic palette knife. Also, the finite paste is applied into the interstice from between the shell rings with the palette knife. The appliance is done inside and outside the shell rings. After the hardening of the paste, its surface is finished by polishing, the resulted dust being removed using a cloth;

- The junction between the shell rings is done by lamination of alternations of glass fibre soaked in resin. The width of the alternations is variable (according to the project), and the length is $600 \mathrm{~mm}$. One alternation is composed of 3 layers:

- 1 mat and 3 mat (material - layer of short fibres with non-oriented disposition;

- 2 tisu (texture - continuous long fibres, with disposition oriented by two perpendicular axes.

Over one support plywood there are prepared 3 series of 3 alternations. More mean a thickening heaviness of the layer which sticks to the vertical wall, and it may be possible to be detached during the time necessary for the resins hardening.

There is applied 1 prepared resin layer (in which it was added hardener and accelerator) over the plywood, the first sheet of material is placed, the resin is applied again, then the next layer and so on, alternating the resin with the necessary glass fibre sheet. 


\subsubsection{Resins processing}

The resin is prepared in small amounts (1-2 litres), by adding Andonox hardener and NL accelerator in variable amounts, with pre-defined limits, in compliance with the temperature and humidity of the work environment. The mixture is achieved by successive adding and homogenization, after each adding. The two used additives should not come in direct contact, the reaction being very exo-thermal. This is why in the work area is brought small amounts of additives that cover the needs of a shift and which are kept away one from the other. The appliance of the binding mixture is carried out using a regular roller (which absorbs liquids). The alternations are glued in the junction area of the shell rings, symmetrically to the junction line by manual pressing, after which the air bubbles resulted from the alternation process are removed.

In the end, the lamination layer is protected with a mixture of paraffin and Hobilo 5150 against UV radiations.

The shell rings that form the chimney are made of polyester reinforced with glass fibre by winding on a cylindrical mould.

FRP (Fibre Reinforced Plastic - Glass fibre reinforced plastic) is a composite material manufactured with a disposal of short and long (or continuous) glass fibres, interspersed with layers of resins, the result of a polymerisation reaction, exo-thermal reaction, between the resin, the hardener and the accelerator.

At the junction of the shell rings, their ends overlap. The between remaining gap due to nonuniformity of the surfaces is loaded with a paste based on resin, The extremities of the two shell rings are welded together using FRP. For achieving the continuity of the thermal-insulation layer, the junction area is covered with polyurethane plates (PUR) the same type as for shell rings, after that it is protected with 4mm FRP plates.

\subsection{The fire}

\subsubsection{Fire development}

The team of workers, disposed on the mobile scaffold inside and outside the shell ring, at the moment of the events occurrence were carrying out the following operations: polishing the surface from the ends of the shell rings and their lamination, applying paste in the interstice between shell rings and lamination, grouting the shell ring, polishing the surface from the area of the metallic guidance clamps, dust removal from the lamination surface.

Post-event statements show that that during the shell ring polishing operation from the western part of the chimney, near him at approximately $1 \mathrm{~m}$, there was a bucket with acetone used for cleaning dirty rollers. After finishing the polishing process, he noticed that the bucket caught fire. He tried to extinguish the fire with the drinking water, but the fire extended. Along with the other colleagues, he left the mobile scaffold and the fires area.

So, near the worker, the presence of a bucket with an industrial solvent which is extremely flammable - acetone, constituted the proper material (combustible atmosphere) for the fires occurrence. Overlapped in time and space with an ignition source, a burning was initiated which got out of control, the flame representing the source of ignition for the combustible elements from the structure of the mobile scaffold, of the reinforced with $4 \mathrm{~mm}$ glass fibre polyester assembly and the body of the shell ring.

\subsubsection{Fire development - elements related to the phenomenology of the fire}

The fire is a complex process, with undetermined evolution, including various phenomena both physical and chemical (burning reactions, heat transfer, flame forming, gases exchange with the environment, structural changes produced in the building materials and reinforcements etc.). Shortly, the fire is an uncontrolled burning.

A fire is generally defined by the following elements:

- The existence of combustible substances and/or materials and the triggering of an ignition source;

- The initiation and uncontrolled development in space and time of the burning process;

- The necessity of and organized intervention in order to interrupt and clear the burning process;

- The causing of losses - following the burning - lives, materials or of other nature;

\section{Research on the Causes}

The identified work equipment and circumstances overlapped in time and space with the ignition source which generated the fire. The analysis of the ignition source was carried out on the categories of sources described as technical causes of fires, in order to establish if it was a human error of a technical 
one. Having the ignition source identified, there was the possibility to reconstruct the scenario of the cause, the existence of favouring factors and the mechanism of the event. At the same time, there were carried out laboratory testings for determining the behaviour to fire of materials used for the chimney.

\subsection{Analysis of ignition sources}

\subsubsection{Electrical energy}

The electrical current can cause the ignition of combustible and flammable substances when the electrical lighting and force facilities are not proper built and operated. An electrical installation can cause a fire if it over-heats or produces sparks, electrical arcs or short-circuit in explosive atmospheres (vapours, gas dust) or in the presence of flammable and combustible substances. Within this category there have been analysed:

- Overheating of electrical conductors;

- Spark and electric arc;

- Short-circuit;

- Static electricity;

- Atmospheric discharges (lightning).

\subsubsection{Mechanical actions}

The mechanical energy which is transformed into heat by friction, hitting, striking, pressure, shock can be a cause of the ignition of combustible substances. Sparks also occur when polishing, sharpening spikes, chisels or other instruments. The frictions followed by over-heating can occur at wheels used for belt transporting, on belts fallen on the axes, on conveyor belts.

\subsubsection{Open-fire}

The forms under which open-fire manifests and may generate fires are the following: open flame of candles, lamps, open-air fires, ignited match, etc. The open flame in contact with easy combustible substances can initiate a burning.

\subsubsection{Incandescent bodies}

The contact between substances and combustible materials with incandescent bodies can cause fires. In incandescent form there may be metals during casting or hot processing, ignited wood, ignited coals, embers in the thrown ashes, lit cigarette, electrical heaters, etc. Un-extinguished matches and cigarette butts thrown away in places with combustible and flammable substances, in fire hazardous places, over flammable sub-stances and easy combustible materials, etc. represent frequently causes of the fires.

\subsubsection{Thermal energy}

Heat transfer from one body to another is done through conductibility, convection or radiation. The thermal radiation is the process of energy transmission in form of electro-magnetic waves, which reaching the body leads to its heating. Thermal radiations can ignite combustible materials even from a larger distance from the heat source.

\subsubsection{Welding}

Electrical welding can be ranked, according to its manifestations (sparks, electrical arc, incandescent particles, etc.), in the group of fire causes provoked by electrical energy, and generally, in the group of open-fire.

\subsubsection{Chemical reactions and solar energy}

Chemical reactions occur with heat release (exo-thermal reactions) or with heat consumption (endothermal reactions).

When using, handling or storing substances that react strongly exo-thermic when coming in contact and may cause fires or explosions.

Solar rays can provoke fires if they are concentrated in the focus of glassware.

\subsection{Laboratory tests on samples of material}

Over samples of material collected from the damaged chimney, from the junction area of the shell rings, on materials and work substances and on protective equipment there were carried out a series of tests, simulating the work environment from that day.

The weather state bulletin was requested from the regional meteorological center.

Tests carried out:

- Burning test for materials from the "shell ring" area;

- Burning test for polyester reinforced with glass fibre $4 \mathrm{~mm}$ and shell ring material of 20-25 mm;

- Burning test for dimethyl-ketone using mechanical spark in open-air, open-flame and lit cigarette;

- Burning test for Polyurethane foam

- Burning test for the mixture of resin dust and glass fiber; 
- Test for determining the surface resistivity of protective footwear;

- Test for determining the surface resistivity of protective clothing.

Following these tests there were drawn up conclusions in the behaviour to burning of the samples and on the identification of the fire initiation source.

\subsection{Possible fire ignition sources}

There were analysed as likely to trigger the event the following:

\subsubsection{Open flames}

Flames, even the very small ones, are the most efficient ignition sources. If a combustible environment is present inside or outside a work point, or in adjacent area, and if an ignition occurs in these places, the flame can easily spread in other places influenced by air currents.

\subsubsection{Mechanical and electro-static generated sparks}

Mechanically generated sparks occur during friction, impact or abrasion processes which lay ground to the solids crushing. The particles are separated from the massif solid, due to the action of mechanical efforts which ensure the necessary energy for defeating the solids cohesion. A part of the energy absorbed from the solid, respectively from detached fragments, is transformed into calorific energy, which in case of detached fragments, taking into account their tiny mass, leads to significant temperature increase until incandescence. If these particles are oxidisable substances, like iron or steel, high temperatures can be reached due to oxidation reactions. Incandescent particles (sparks) can ignite gases and flammable vapours as well as air-dust mixtures (especially in some mixtures of metallic dust with the air). The sparks generated mechanically can also initiate the burning of dust deposits, triggering the smouldering phenomenon.

The electro-static spark represents a discharge between two conductors, liquid or solid ones. It is characterized by a pulsed channel, well-defined, which carries a high intensity current. The ionization of the gas in the channel is complete, over its entire lengths. The discharge is very fast and creates a sound like a harsh popping.

Sparks occur between conductors when the intensity of the electrical field exceeds the electrical resistance of the atmosphere. The potential difference between the conductors required for the breakthrough depends on the form and on the distance from between the conductors. Generally, the breakthrough resistance for flat surfaces with equal radius or larger than $10 \mathrm{~mm}$ is around $3 \mathrm{MV} \mathrm{m}^{-1}$ in normal air and increases once with the decrease of the distance from between the conductors.

Because the objects between which sparks occur are conductors, most of the stored loads will pass into sparks. In most cases, these one dissipate almost all the stored energy.

Due to the on-site expertise of the event and of the studying of documents supplied, available working equipment from the mobile scaffold, work substances with a high flammability risk and taking into account the results of the burning tests and determination of electrical resistances and resistivities of personal protective equipment, carried on in experimental laboratory testings, from samples of materials collected from the place of the events occurrence, which have denied in all cases the hypothesis of flammable liquid (acetone) ignition with mechanical or electro-static spark, it resulted that: the ignition source which led to the occurrence of fire was the open-flame

In addition, the argument that reinforces the belief, that at the time of the event open-flame was used when working, consists in the identification of cigarettes packaging, brands Marlboro, Kent and Winchester), at the base of the mobile scaffold, where there was not a special place set up for smoking. From the three workers that were on the mobile scaffold outside of the shell ring, at the time of fire triggering, two are smokers. According to their statements, their preferred cigarettes are Kent brand.

\subsection{Cause of the event occurrence}

The cause of the fire was the ignition of the acetone from the bucket located on the platform, having open-flame as ignition source. One worker tried to extinguish the fire using the drinking water that he had with him, but the fire extended over the external assembly of the joint from shell ring no.9 and shell ring no.10, and over the wooden floor of the mobile scaffold. The assembly of the shells cover caught fire (4 mm FRP material - very flammable) - polyurethane - alternations (successive layers of resin with glass fibre) and resin, the flame and heat of the fire spreading from shell ring to shell ring, on the exterior part, south-western area, until the higher elevation of the chimney under construction.

\subsection{Contributory factors}

Following the imprinting of the event, the theoretical and practical studies carried out and regarding the events phenomenon, it is concluded that the contributory factors were the following:

- Over-supply of the fire with required oxygen for the burning process (wind with a speed up to 45 $\mathrm{km} / \mathrm{h})$; 
- The existence of an ascending stream of xylene vapours from the rubberizing operation from the bottom part of the desulphurisation installation which contributed to maintaining and enhancing of the fire;

- The existence of combustible materials (wood) from the structure of the mobile scaffold, as well as plywood plates over which the grouting material needed for the interstice from between the shell rings was processed.

- Work substances (resins, reaction accelerator and hardener, UV protective substances) with high flammability risk;

- Atmosphere rich in resin dust particles (flammable element) and glass fibre from the polishing operation;

- Low level of training of the workers from the platform

\subsection{The mechanism of the event occurrence}

The performed modelling which simulate the phases of the of the fire finally triggered, confirm the primary ignition of acetone, after that this fire initiated the ignition of the plywood plates from the mobile scaffold structure, of available substances from the scaffold, separately from the bucket with acetone (20 l container with acetone and a bottle with resin) and the external joint area assembly from shell ring no.9 and no.10.

This fire developed and represented the ignition source for the higher shell rings, through flame propagation, heat transmission, combustible elements from the shell rings structure heating and the triggering of the combustion reaction.

\section{Conclusions}

1. The event from the chimney of the desulphurisation installation, from within the thermal-power plant was a fire generated by a human error.

2. Combustible materials involved in the fire were: acetone, resins from the chill, resin (last layer) from the shell rings, protective paraffin layer from the shell rings, plywood from the mobile scaffold.

3. Ignition source of the primary fire, most probably was of thermal nature, open-flame type.

4. Cause of the fire was the ignition of the acetone from the bucket from the platform, having openflame as source.

5. The mechanism of the fire had as starting point the primary ignition of acetone, which initiated the ignition of the plywood plates from the mobile scaffold structure and from the external joint area assembly from shell ring no.9 and no.10. , this fire, by its development, represented the ignition source for the higher shell rings, through flame propagation, heat transmission, combustible elements from the shell rings structure heating and the triggering of the combustion reaction.

6. Favouring factors for the fires development and propagation:

- Wind speed up to $45 \mathrm{~km} / \mathrm{h}$-oxygen over-supply;

- existence of xylene vapours from the rubberizing operation from the bottom part of the desulphurator;

- existence of combustible materials (wood) from the structure of the mobile scaffold, as well as plywood plates over which the grouting material needed for the interstice from between the shell rings was processed.

- resins, reaction accelerator and hardener, UV protective substances with high flammability risk;

- Low level of training of the workers from the platform.

\section{References}

- Technical Documentation, Construction of the wet smoke chimney of the absorber of the gas desulphurization facility,

- INCD-INSEMEX Petroşani, Technical expertise regarding the causes and circumstances that led to the occurrence of the event dated [...] 2011, at the working point of the absorber of the gas desulphurization facility [...], (in Romanian) Petrosani, 2011

- Balulescu P., Fire prevention, (in Romanian), technical publishing house, Bucharest, Romania, 1979 